\title{
Continuous Synthesis of a Green Fuel Additive Mixture with Highest Quantities of Solketalacetin and Solketal and Lowest Amount of Diacetin from Biodiesel-Derived Glycerol
}

\author{
Yadollah M. Gorji and Hassan S. Ghaziaskar* \\ Department of Chemistry, Isfahan University of Technology, 84156-83111 Isfahan, Iran
}

\begin{abstract}
This work presents a continuous, easy-to-scale-up system for glycerol conversion to a valuable fuel additive mixture such as solketalacetin ((2,2-dimethyl-1,3-dioxolan-4-yl)methyl acetate), solketal and minimum amount of diacetin with no byproducts. A two-stage reaction was conducted to synthesize the mixture. At first, glycerol was reacted with acetic acid in a continuous system to synthesize monoacetin using a small plug flow reactor and central composite design to optimize the variables related to monoacetin synthesis. Finally, an acetic acid:glycerol mole ratio of 3.7:1, a temperature of $79^{\circ} \mathrm{C}$, a flow rate of $0.9 \mathrm{~mL} \mathrm{~min}^{-1}$, and a pressure of 1 bar were determined as the optimum conditions. At the optimum condition, predicted and experimental yields of monoacetin were 63 and $62 \%$, respectively. In the next stage, monoacetin and the residual glycerol were reacted with acetone to obtain a mixture of solketalacetin, solketal, and diacetin with the mole percentage of 62,30 , and $8 \%$, respectively.
\end{abstract}

Keywords: biodiesel additive, monoacetin, solketalacetin, (2,2-dimethyl-1,3-dioxolan-4-yl) methyl acetate, central composite design

\section{Introduction}

Biodiesel is a renewable energy source that is synthesized via transesterification of the vegetable oil triglycerides. ${ }^{1}$ In this process, glycerol is produced as a byproduct that accounts for approximately $10 \mathrm{wt}$. $\%$ of the biodiesel produced. ${ }^{2,3}$ One of the uses of glycerol is its chemical transformation into oxygenated fuel additives. ${ }^{4-10}$ Glycerol can be reacted with acetone to produce solketal., ${ }^{4,11,12}$ Moreover, glycerol can react with acetic acid to produce monoacetin (MA), diacetin (DA), and triacetin (TA). ${ }^{13,18}$ Although triacetin is one of the best biofuel additives, the process of triacetin synthesis is costly and requires high mole ratio of acetic acid:glycerol, high temperatures, and pressures. ${ }^{6,13,19,20}$ Garcia et al. ${ }^{21}$ synthesized solketalacetin ((2,2-dimethyl-1,3-dioxolan-4-yl)methyl acetate), whose properties were in some respects superior to those of triacetin as a biodiesel additive, but they used acetic anhydride and triethylamine to synthesize solketalacetin that is not suitable for industrial process due to the cost of these materials, and health and safety problems. They indicated that solketalacetin is a better viscosity improver and does not increase the density as much as triacetin. In our previous work, ${ }^{22}$ a novel method was developed for the synthesis of solketalacetin consisting of two stages. In the first stage, a

*e-mail: ghazi@cc.iut.ac.ir mixture was obtained from the reaction of glycerol and acetic acid in a batch system with the mole percentage of 60, 31, 4 and $5 \%$, for monoacetin, diacetin, triacetin, and the residual glycerol, respectively. In the second stage, solketalacetin was obtained from the reaction of monoacetin with acetone in a continuous system. The final mixture composition changed to solketalacetin, solketal, diacetin, and triacetin with the mole percentage of $60,5,31$, and $4 \%$, respectively. ${ }^{22}$

Among the fuel additives synthesized from glycerol, triacetin and solketalacetin, are the superior ones followed by solketal. Diacetin and monoacetin, however, do not meet the diesel and biodiesel fuel requirements of American and European Standards (ASTM D 6751 and EN 14214, respectively). ${ }^{21,23,24}$ Diacetin and monoacetin impart high density and viscosity when mixed with the biodiesel, and the latter does not deliver a satisfactory performance with respect to its pour point and cold filter plugging point due to diacetin and monoacetin low melting point and high boiling point. ${ }^{23}$ Moreover, diacetin and monoacetin have low solubility in the biodiesel and reduce its oxidation stability. ${ }^{23}$ These concerns have led us to the conclusion that the final mixture in our previous work, due to its high diacetin content $(31 \%)$, lack the expected properties to use it as a desirable fuel additive. Therefore, for the sake of scaling up our previous project, we decided to improve the production procedure to increase the mole percentage 
of solketalacetin and/or solketal and to reduce the amount of diacetin in the final mixture. This requires an increase in the mole percentage of monoacetin with the residual glycerol in the first stage of the reaction as both reacts with acetone in the second stage (Figure 1).
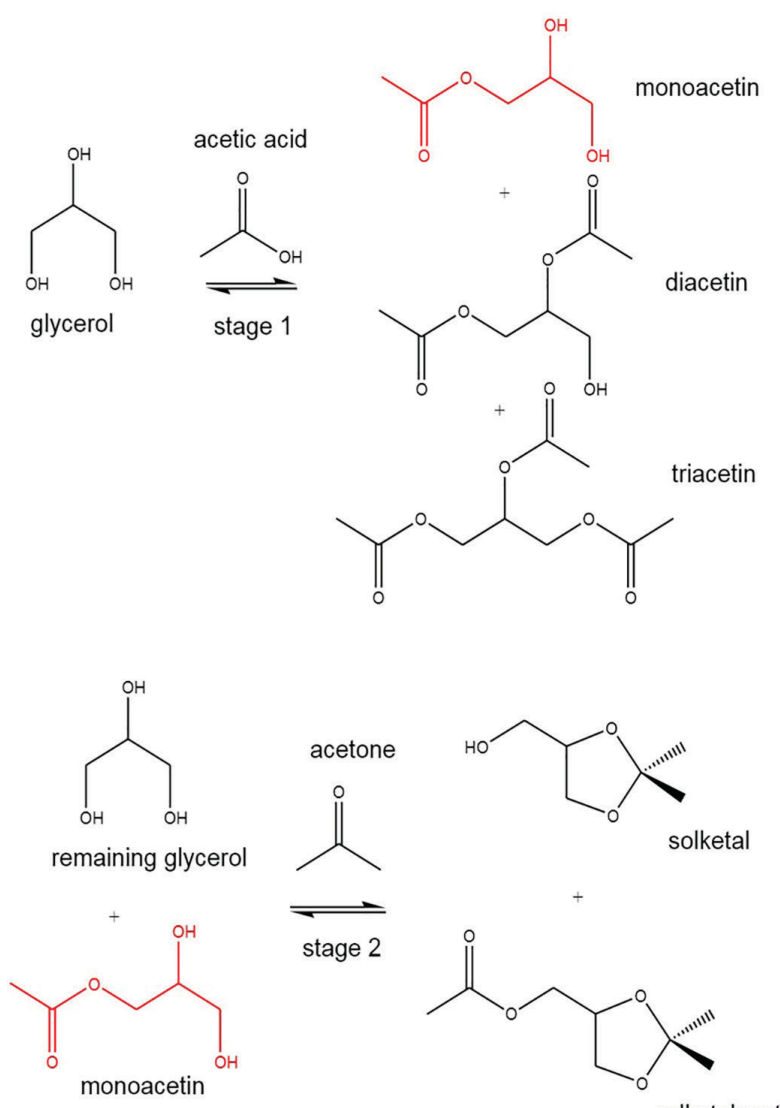

Figure 1. Synthesis of solketalacetin and solketal in two stages. Stage 1: reaction of glycerol with acetic acid to produce monoacetin; stage 2: reaction of monoacetin and remaining glycerol with acetone to produce solketalacetin and solketal.

Reaction of glycerol with acetic acid is a consecutive one and monoacetin is an intermediate compound in this reaction. ${ }^{25}$ Zhou et al. ${ }^{26}$ showed that in the presence of an acidic catalyst, the rate constant of the reaction between acetic acid and glycerol was higher than that of the reaction between acetic acid and either monoacetin or diacetin. Therefore, monoacetin yield might be increased if the reaction between acetic acid and glycerol is accomplished in a short residence time in a plug flow reactor. ${ }^{27}$ The objective of the present work was to produce a mixture with the highest mole percentage of solketalacetin and solketal, and the lowest amount of diacetin and monoacetin at the final mixture to be used as fuel additive. The first stage of the reaction (Figure 1) had to be conducted under conditions that would yield the highest monoacetin quantity, but the lowest amount of diacetin. In the second stage, the whole amount of monoacetin and the residual glycerol would react with acetone to produce solketalacetin and solketal. For this purpose, a continuous system with a low-volume plug flow reactor for the first stage of the reaction was used as the easy to scale up procedure for synthesizing monoacetin. ${ }^{25}$ The central composite design (CCD) and the response surface methodology (RSM) were employed to optimize the variables involved in the first stage of the reaction to yield the highest amount of monoacetin and the lowest amount of diacetin.

\section{Experimental}

\section{Material and methods}

Acetic acid (purity > 99.85\%), glycerol (purity > 99.9\%) and acetone (purity $>99 \%$ ) were purchased from Fanavaran Petrochemical Co. (Tehran, Iran), Emery Oleochemicals (Kuala Lumpur, Malaysia) and Sasol Co. (Johannesburg, South Africa), respectively. Triacetin (purity > 99\%) and diacetin (purity ca. 50\%) were purchased from Fluka (Seelze, Germany). Solketal, monoacetin and solketalacetin were synthesized via the previously reported method and verified by gas chromatography with flame ionization detector (GC-FID, purity > 95\%). ${ }^{21,26}$ Amberlyst 36 were purchased from Sigma-Aldrich (Munich, Germany). Methanol and 2-ethyl-1-hexanol were purchased from Merck Co. (Darmstadt, Germany).

\section{Reaction of glycerol with acetic acid}

Monoacetin formation via glycerol acetylation using acetic acid was carried out in a continuous flow system. A small plug flow reactor consisted of a stainless steel tube ( $8 \mathrm{~mm}$ i.d. and $3.2 \mathrm{~cm}$ length), which had been filled with $0.9 \mathrm{~g}$ dried Amberlyst 36 as the catalyst before placing in an oven equipped with a temperature controller $\left( \pm 1^{\circ} \mathrm{C}\right)$.

The required pressure $( \pm 1$ bar) was created via a backpressure regulator (model BP 1580-81, JASCO Co.). Feedstock solution was continuously pumped into the reactor at different pressure and flow rates using a high-performance liquid chromatography (HPLC) pump (model PU-980, JASCO Co.) (Figure S1 of Supplementary Information). Samples were collected in a cold trap and finally analyzed using GC-FID.

\section{Sample analysis procedure}

Analyses of the samples in different experiments were carried out using a GC-FID (model SP-3420, Beifen-Ruili Analytical Instrument Co., Ltd., Beijing, China). The 
carrier gas was argon and the capillary column of HP-5 with $30 \mathrm{~m}$ length, $0.25 \mathrm{~mm}$ i.d., and $0.25 \mu \mathrm{m}$ film thickness was used.

The GC injection port and the detector temperature were set at 290 and $300{ }^{\circ} \mathrm{C}$, respectively. Methanol was used as the solvent in the sample preparations and then $0.4 \mu \mathrm{L}$ of the sample was injected into the GC-FID. The temperature programming was used for the $\mathrm{GC}$ analysis. The initial column temperature was set at $80^{\circ} \mathrm{C}$ for $3 \mathrm{~min}$ and subsequently increased to $90^{\circ} \mathrm{C}$, at a rate of $3{ }^{\circ} \mathrm{C} \mathrm{min}^{-1}$. Then it was increased from 90 to $280{ }^{\circ} \mathrm{C}$ at the rate of

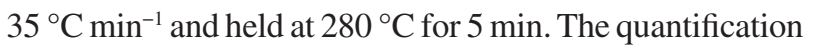
was performed by adding an internal standard (2-ethyl1-hexanol) to the solutions and integrating the peak areas to establish the calibration curve.

The yield, conversion and selectivity of the reaction products and the residual glycerol in the solution were calculated using the following equations:

Yield $(\%)=\frac{\text { moles of each product }}{\text { initial moles of glycerol }} \times 100$

Residual glycerol $(\%)=\frac{\text { moles of remaining glycerol }}{\text { initial moles of glycerol }} \times 100$

Conversion $(\%)=\frac{\text { initial moles of glycerol }- \text { remaining moles of glycerol }}{\text { initial moles of glycerol }} \times 100$

Selectivity $(\%)=\frac{\text { moles of each product }}{\text { moles of reacted glycerol }} \times 100$

The residual glycerol was calculated since the glycerol that did not react in the first stage can react later with acetone in the second stage and produce solketal.

\section{Experimental design}

The CCD was used as the experimental design; the RSM was employed to optimize the reaction variables, i.e., the mole ratio of the acetic acid:glycerol, temperature, pressure, and feed flow rate. The variables and their values in each experiment are presented in Table 1.

Since our goal was to find the best conditions for the synthesis of monoacetin in the first stage, a full quadratic equation (equation 5) was employed using RSM to show the interaction variables for the monoacetin yield.

$Y=b_{0}+\sum_{i}^{k} b_{i} x_{i}+\sum_{i}^{k} b_{i j} x_{i}^{2}+\sum_{i}^{k} \sum_{j}^{1} b_{i j} x_{i} x_{j}$

where, $\mathrm{Y}$ is the monoacetin yield; $\mathrm{b}_{0}, \mathrm{~b}_{\mathrm{i}}, \mathrm{b}_{\mathrm{ii}}$, and $\mathrm{b}_{\mathrm{ij}}$ are the coefficients for the intercept, linearity, square, and interaction terms, respectively; and $\mathrm{x}_{\mathrm{i}}$ and $\mathrm{x}_{\mathrm{j}}$ are independent variables.

\section{Results and Discussion}

Fitting the model for monoacetin yield

The value of the coefficients in each model was calculated using RSM and their significance was determined by analysis of variance (ANOVA), as shown in Table S1 (Supplementary Information (SI) section). The variables with $p$-values (representing the likelihood of a parameter's coefficient to be zero) greater than 0.05 were interpreted as insignificant and, therefore, were deleted. The lack-of-fit of the model, which indicated the validity of the model, was determined using ANOVA; the results are summarized in Table S2 (SI section). These data revealed that the model fitted the experimental data $(p>0.05)$ and that there was a good correlation between the responses and the independent variables.

The relationship between monoacetin yield and the variables was captured by equation 6 .

$$
\begin{aligned}
& \mathrm{Y}=-58.99+40.80(\mathrm{X})+1.077(\mathrm{~T})+8.661(\mathrm{~F})+ \\
& 0.1542(\mathrm{P})-4.164(\mathrm{X})^{2}-0.0038(\mathrm{~T})^{2}-4.657(\mathrm{~F})^{2}- \\
& 0.1281(\mathrm{XT})-0.0575(\mathrm{XP})
\end{aligned}
$$

where, $\mathrm{X}$ is the acetic acid to glycerol mole ratio, $\mathrm{T}$ the temperature, $\mathrm{F}$ the flow rate and $\mathrm{P}$ is the pressure.

Four plots are shown in Figure S2 (SI section) illustrating that the residuals were used to ensure the experiment design was randomized in the run order, and specify that the designed experiments were randomized.

\section{Effects of variables on monoacetin yield}

The effects of different variables on monoacetin yield were investigated by using both equation 6 and visual inspection of the contour plots and the surface plots of monoacetin yield versus independent variables (Figure 2). A brief description of how the effect of each variable was determined is as follows:

\section{Effect of acetic acid to glycerol mole ratio}

As shown in Table 1, the surface plots (Figures 2a-2c), and the contour plots (Figures $2 \mathrm{~g}$-2i), increasing acetic acid:glycerol mole ratio has two different effects on the monoacetin yield. Monoacetin yield increased at low mole ratios of acetic acid:glycerol, but declined at the high ratios. In equilibrium reactions, increasing the reactant concentration increases products concentration, but in consecutive reactions, increasing the reactant concentration can produce all the products of the next steps. Reaction of glycerol with acetic acid is a consecutive one. ${ }^{25}$ Increasing 
Table 1. Experiments designed by central composite design (CCD) and the experimental yields

\begin{tabular}{|c|c|c|c|c|c|c|c|c|}
\hline \multirow{2}{*}{ Experiment No. } & \multicolumn{4}{|c|}{ Variable } & \multicolumn{4}{|c|}{ Yield / \% } \\
\hline & $\mathrm{X}$ & $\mathrm{T} /{ }^{\circ} \mathrm{C}$ & $\mathrm{F} /\left(\mathrm{mL} \mathrm{min}^{-1}\right)$ & $\mathrm{P} /$ bar & MA & DA & TA & Byproduct \\
\hline 1 & 3 & 100 & 0.1 & 50 & 58 & 30 & 1 & 0 \\
\hline 2 & 4 & 80 & 1.6 & 25 & 59 & 25 & 2 & 0 \\
\hline 3 & 3 & 100 & 1.1 & 50 & 59 & 26 & 2 & 0 \\
\hline 4 & 4 & 120 & 0.6 & 75 & 44 & 47 & 6 & 3 \\
\hline 5 & 4 & 120 & 1.6 & 25 & 51 & 36 & 5 & 1 \\
\hline 6 & 2 & 120 & 0.6 & 75 & 58 & 23 & 2 & 0 \\
\hline 7 & 4 & 80 & 0.6 & 75 & 54 & 32 & 3 & 0 \\
\hline 8 & 3 & 100 & 1.1 & 50 & 57 & 27 & 2 & 0 \\
\hline 9 & 4 & 120 & 0.6 & 25 & 49 & 45 & 3 & 2 \\
\hline 10 & 2 & 80 & 1.6 & 25 & 49 & 9 & 0 & 0 \\
\hline 11 & 3 & 100 & 1.1 & 1 & 62 & 24 & 0 & 0 \\
\hline 12 & 3 & 100 & 1.1 & 50 & 60 & 28 & 2 & 0 \\
\hline 13 & 3 & 100 & 1.1 & 50 & 59 & 28 & 2 & 0 \\
\hline 14 & 2 & 80 & 0.6 & 75 & 55 & 14 & 1 & 0 \\
\hline 15 & 2 & 80 & 0.6 & 25 & 54 & 13 & 0 & 0 \\
\hline 16 & 4 & 80 & 1.6 & 75 & 55 & 30 & 2 & 0 \\
\hline 17 & 3 & 140 & 1.1 & 50 & 50 & 40 & 6 & 4 \\
\hline 18 & 3 & 60 & 1.1 & 50 & 57 & 17 & 0 & 0 \\
\hline 19 & 1 & 100 & 1.1 & 50 & 41 & 7 & 0 & 0 \\
\hline 20 & 3 & 100 & 1.1 & 100 & 59 & 31 & 1 & 0 \\
\hline 21 & 2 & 80 & 1.6 & 75 & 50 & 12 & 0 & 0 \\
\hline 22 & 2 & 120 & 1.6 & 75 & 54 & 16 & 1 & 0 \\
\hline 23 & 2 & 120 & 0.6 & 25 & 54 & 21 & 1 & 0 \\
\hline 24 & 5 & 100 & 1.1 & 50 & 45 & 44 & 5 & 1 \\
\hline 25 & 3 & 100 & 1.1 & 50 & 60 & 29 & 1 & 0 \\
\hline 26 & 3 & 100 & 2.1 & 50 & 52 & 22 & 0 & 0 \\
\hline 27 & 4 & 80 & 0.6 & 25 & 58 & 27 & 2 & 0 \\
\hline 28 & 3 & 100 & 1.1 & 50 & 60 & 28 & 1 & 0 \\
\hline 29 & 3 & 100 & 1.1 & 50 & 61 & 27 & 1 & 0 \\
\hline 30 & 2 & 120 & 1.6 & 25 & 51 & 16 & 1 & 0 \\
\hline 31 & 4 & 120 & 1.6 & 75 & 50 & 41 & 3 & 2 \\
\hline
\end{tabular}

X: acetic acid to glycerol mole ratio: T: temperature; P: pressure; F: flow rate; MA: monoacetin; DA: diacetin; TA: triacetin.

acetic acid:glycerol mole ratio, first increased monoacetin mole ratio, but then monoacetin reacted with excess acetic acid and produced diacetin. Therefore, the reaction passed a maximum value of monoacetin before its decrease. ${ }^{26}$ The monoacetin yield had its maximum values at 2.5-3.5 mole ratios. The optimum amount will be specified in Monoacetin yield optimization section.

\section{Effect of temperature}

All three steps of the reaction between glycerol and acetic acid are endothermic; however, thermodynamic calculations have shown that the standard Gibbs free energy of the monoacetin is less than that of the diacetin and triacetin. ${ }^{27}$ Also, by increasing the temperature, the reaction rate increased and facilitated the distribution of the esters toward diacetin and triacetin. ${ }^{27}$ Melero et al. ${ }^{28}$ found that at high mole ratio of acetic acid:glycerol, the high temperature suppressed the formation of monoacetin and increased the formation of diacetin and triacetin. Hence, at low temperatures $\left(60-70{ }^{\circ} \mathrm{C}\right)$, by rising reaction temperature, the monoacetin yield increased, while at higher temperatures $\left(90-100{ }^{\circ} \mathrm{C}\right)$, diacetin and triacetin concentration increased.

As shown in Table 1 and Figure 2 (c, e, f, g, j, and $\mathrm{k})$, monoacetin yield had its highest values at moderate temperatures $\left(80-90{ }^{\circ} \mathrm{C}\right)$.

\section{Effect of flow rate}

Table 1 and Figure 2 (b, d, f, h, j, and l) show the effect of flow rate on monoacetin yield. Clearly, at high flow rates, lowering the flow rate increased the monoacetin yield. Reducing flow rate led to an enhanced reactant-catalyst contact time and increased the monoacetin yield. At low flow rates, however, monoacetin yield decreased when the 

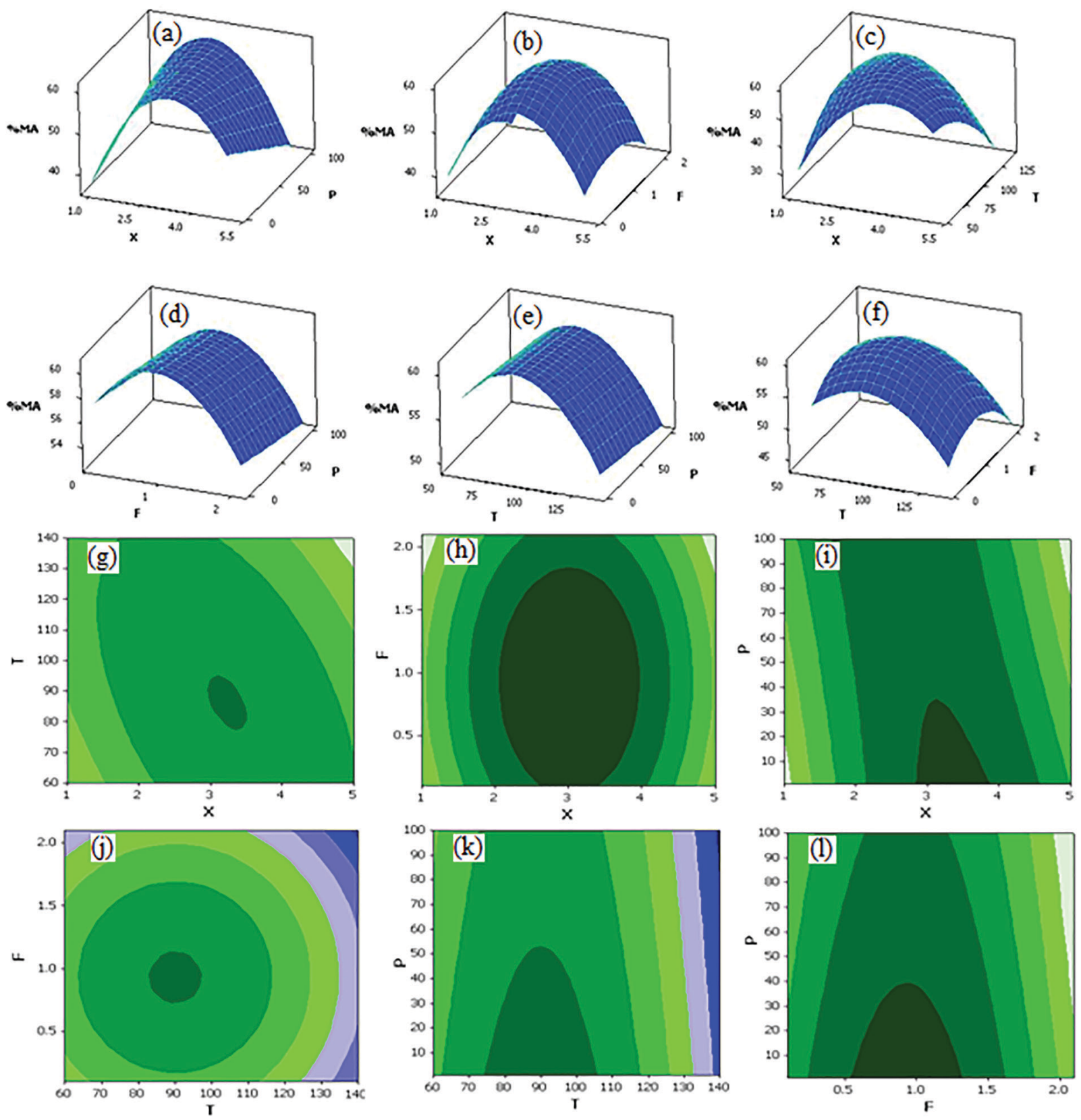

Figure 2. Surface plots and contour plots of monoacetin yields versus different variables.

flow rate was reduced because as monoacetin and excessive acetic acid are in vicinity of the catalyst for longer time, that facilitated the distribution toward diacetin and triacetin. By examining the surface plots, and the contour plots of Figure 2, we comprehend that in a flow rate of $0.9 \mathrm{~mL} \mathrm{~min}^{-1}$, the highest monoacetin yield has been attained.

\section{Effect of pressure}

As shown in Figure 2 (a, d, e, i, k, and l), monoacetin yield reduced by increasing the reaction pressure, since the reaction proceeded in synthesizing diacetin and triacetin. Clearly, the acetylation of glycerol must be conducted at low (ambient) pressure in order to increase the monoacetin yield.

\section{Monoacetin yield optimization}

The optimum conditions for synthesis of monoacetin with high yield and the effect of each variable were determined using RSM, as shown in Figure S3 (SI section) and summarized in Table 2 . The monoacetin yield predicted by RSM was $63 \%$ under the optimum conditions, while the experimental yield under the same conditions was $62 \%$. Moreover, the experimental yield values recorded 
for diacetin, triacetin, and the residual glycerol were 8,0 , and 30\%, respectively. Figure S4 (SI section) presents the GC-FID chromatogram of the solution obtained for the monoacetin yield under the optimum conditions.

Table 2. Optimum conditions for monoacetin yield determined by response surface methodology (RSM)

\begin{tabular}{lc}
\hline Variable & Optimum condition \\
\hline $\mathrm{X}$ & 3.7 \\
$\mathrm{~T} /{ }^{\circ} \mathrm{C}$ & 79 \\
$\mathrm{~F} /\left(\mathrm{mL} \mathrm{min}^{-1}\right)$ & 0.9 \\
$\mathrm{P} /$ bar & 1 \\
\hline
\end{tabular}

$\mathrm{X}$ : acetic acid to glycerol mole ratio; T: temperature; F: flow rate; P: pressure.

To compare the results of this work with other works reported, ${ }^{15,20,22,26,29-31}$ the selectivity and conversion of monoacetin, diacetin and triacetin are summarized in Table 3. Since diacetin is not easy to separate and the solketal solubility is not high enough in biofuel and gasoline to be used as a fuel additive, and the reaction of glycerol with acetic acid is a reversible consecutive reaction, our continuous, easy-to-scale-up system for glycerol conversion in acetic acid is preferred because it has resulted in the lowest amount of diacetin and highest amount of monoacetin, as shown in Table 3.

\section{Reaction with acetone}

In our previous work, the optimum conditions for ketalization of the monoacetin was determined as follows: an acetone to monoacetin mole ratio of 9 , a reaction temperature of $20^{\circ} \mathrm{C}$, a flow rate of $0.2 \mathrm{~mL} \mathrm{~min}^{-1}$, a pressure of $45 \mathrm{bar}$, and $2.0 \mathrm{~g}$ Purolite PD 206 used as the catalyst. ${ }^{22}$ Ketalization of the solution in stage 1 was conducted under these optimum conditions to obtain a mixture with the following mole percentage: solketalacetin $=62 \%$, solketal $=30 \%$, and diacetin $=8 \%$ with no byproducts. Figure S4 (SI section) presents the GC-FID chromatogram of the final solution.

\section{Conclusions}

A mixture with the maximum amount of solketalacetin or solketal and minimum amount of diacetin with no monoacetin was synthesized in two stages. In the first stage, a low-volume plug flow reactor containing $0.9 \mathrm{~g}$ of Amberlyst 36 as the catalyst was used for reacting glycerol with acetic acid. The following optimum reaction conditions were obtained by RSM for the first stage as acetic acid:glycerol mole ratio 3.7:1; reaction temperature, $79^{\circ} \mathrm{C}$; flow rate, $0.9 \mathrm{~mL} \mathrm{~min}^{-1}$; and pressure, $1 \mathrm{bar}$. The predicted and experimental values of the monoacetin yield were 63 and $62 \%$, respectively. In the second stage of the process, the mixture of monoacetin $(62 \%)$, glycerol $(30 \%)$ and $8 \%$ diacetin was reacted with acetone under the optimum conditions..$^{22}$ Finally, a suitable mixture as biofuel additive was obtained with the mole percentage values of solketalacetin, solketal, and diacetin as 62,30 , and $8 \%$, respectively.

\section{Supplementary Information}

Supplementary information is available free of charge at http://jbcs.sbq.org.br as PDF file.

\section{Acknowledgments}

The authors are thankful to Professor Keikhosro Karimi from Isfahan University of Technology (Iran) for his suggestions on some aspects of this research.

Table 3. Comparison of the selectivity and yield percentages for glycerol acetylation with acetic acid reported in different literatures compared to this work

\begin{tabular}{|c|c|c|c|c|c|c|c|c|c|}
\hline \multirow{2}{*}{ entry } & \multicolumn{3}{|c|}{ Selectivity / \% } & \multirow{2}{*}{$\begin{array}{c}\text { Glycerol } \\
\text { conversion / \% }\end{array}$} & \multicolumn{3}{|c|}{ Yield / \% } & \multirow{2}{*}{ Setup } & \multirow{2}{*}{ Reference } \\
\hline & MA & $\mathrm{DA}$ & $\mathrm{TA}$ & & MA & $\mathrm{DA}$ & $\mathrm{TA}$ & & \\
\hline 1 & 93.0 & 7.0 & N.D. & 53.0 & $49.3^{\mathrm{a}}$ & $3.7^{\mathrm{a}}$ & N.D. & continuous & 15 \\
\hline 2 & 75.0 & 23.0 & 2.0 & 95.0 & $71.2^{\mathrm{a}}$ & $21.8^{\mathrm{a}}$ & $1.9^{\mathrm{a}}$ & continuous & 18 \\
\hline 3 & 62.5 & 33.5 & 4.0 & 95.0 & $59.4^{\mathrm{a}}$ & $31.8^{\mathrm{a}}$ & $3.8^{\mathrm{a}}$ & continuous & 20 \\
\hline 4 & 89.0 & 11.0 & N.D. & 70.0 & 62.0 & 8.0 & $<1$ & continuous & this work \\
\hline 5 & $84.7^{\mathrm{a}}$ & $13.8^{\mathrm{a}}$ & $1.5^{\mathrm{a}}$ & 73.2 & 62.0 & 10.1 & 1.1 & batch & 24 \\
\hline 6 & 41.7 & 49.3 & 9.0 & 98.5 & $41.1^{\mathrm{a}}$ & $48.6^{\mathrm{a}}$ & $8.8^{\mathrm{a}}$ & batch & 27 \\
\hline 7 & 60.5 & 25.8 & 13.7 & 96.3 & $58.2^{\mathrm{a}}$ & $24.8^{\mathrm{a}}$ & $13.0^{\mathrm{a}}$ & batch & 27 \\
\hline 8 & 88.9 & 11.1 & N.D. & 50.7 & $45.1^{\mathrm{a}}$ & $5.6^{\mathrm{a}}$ & N.D. & batch & 28 \\
\hline 9 & 88.1 & 11.6 & 0.3 & 59.4 & $52.3^{\mathrm{a}}$ & $6.9^{\mathrm{a}}$ & N.D. & batch & 29 \\
\hline
\end{tabular}

These results are calculated based on the data reported in the references. MA: monoacetin; DA: diacetin; TA: triacetin; N.D.: not detected. 


\section{References}

1. Ma, F.; Hanna, M.; Bioresour. Technol. 1999, 70, 1.

2. Kim, H. J.; Kang, B. S.; Kim, M. J.; Park, Y. M.; Kim, D. K.; Lee, J. S.; Catal. Today 2004, 93, 315.

3. Gerpen, J. V.; Fuel. Process. Technol. 2005, 86, 1097.

4. Shirani, M.; Ghaziaskar, H. S.; Xu, C.; Fuel. Process. Technol. 2014, 124, 206.

5. Agirre, I.; Garcia, I.; Requies, J.; Barrio, V. L.; Guemez, M. B.; Canbra, J. F.; Arias, P. L.; Biomass Bioenergy 2011, 35, 3636.

6. Silva, P. H. R.; Gonçalves, V. L. C.; Mota, C. J. A.; Bioresour. Technol. 2010, 101, 6225.

7. Konwar, L. J.; Arvela, P. M.; Begum, P.; Kumar, N.; Thakur, A. J.; Mikkola, J. P.; Deka, R. C.; Deka, D.; J. Catal. 2015, 329, 237.

8. Nanda, M. R.; Yuan, Z.; Qin, W.; Ghaziaskar, H. S.; Poirier, M. A.; Xu, C.; Appl. Energy 2014, 123, 75.

9. Fan, X.; Burton, R.; Zhou, Y.; Open Energy Fuels J. 2010, 3, 17.

10. Deutsch, J.; Martin, A.; Lieske, H.; J. Catal. 2007, 245, 428.

11. Oliveira, P. A.; Souza, R. O. M. A.; Mota, C. J. A.; J. Braz. Chem. Soc. 2016, 27, 1832.

12. Nanda, M. R.; Yuan, Z.; Qin, W.; Ghaziaskar, H. S.; Poirier, M. A.; Xu, C.; Fuel 2014, 128, 113.

13. Rezayat, M.; Ghaziaskar, H. S.; Green Chem. 2009, 11, 710.

14. Nebel, B.; Mittelbach, M.; Uray, G.; Anal. Chem. 2008, 80, 8712.

15. Rastegari, H.; Ghaziaskar, H. S.; J. Ind. Eng. Chem. 2015, 21, 856.

16. Khayoon, M. S.; Hameed, B. H.; Bioresour. Technol. 2011, 102, 9229.
17. Rastegari, H.; Ghaziaskar, H. S.; Yalpani, M.; Shafiei, A.; Energy Fuels 2017, 31, 8256.

18. Zhou, C. H.; Beltramini, J. N.; Fan, Y. X.; Lu, G. Q.; Chem. Soc. Rev. 2008, 37, 527.

19. Shafiei, A.; Rastegari, H.; Ghaziaskar, H. S.; Yalpani, M.; Biofuel Res. J. 2017, 13, 565.

20. Rastegari, H.; Ghaziaskar, H. S.; Yalpani, M.; Ind. Eng. Chem. Res. 2015, 54, 3279.

21. Garcia, E.; Laca, M.; Perez, E.; Garrido, A.; Peinado, J.; Energy Fuels 2008, 22, 4274.

22. Gorji, Y. M.; Ghaziaskar, H. S.; Ind. Eng. Chem. Res. 2016, 55, 6904.

23. Melero, J. A.; Vicente, G.; Morales, G.; Paniagua, M.; Bustamante, J.; Fuel 2010, 89, 2011.

24. Mota, C. J. A.; da Silva, C. X. A.; Rosenbach, N.; Costa, J.; da Silva, F.; Energy Fuels 2010, 24, 2733.

25. Levenspiel, O.; Chemical Reaction Engineering, $3^{\text {rd }}$ ed.; Wiley: New York, USA, 1998.

26. Zhou, L.; Nguyen, T. H.; Adesina, A. A.; Fuel Process. Technol. 2012, 104, 310.

27. Liao, X.; Zhu, Y.; Wanga, S. G.; Chen, H.; Li, Y.; Appl. Catal., B 2010, 94, 64 .

28. Melero, J. A.; Grieken, R.; Morales, G.; Paniagua, M.; Energy Fuels 2007, 21, 1782.

29. Mufrodi, Z.; Rochmadi, R.; Sutijan, S.; Budiman, A.; Eng. J. 2014, 18, 29.

30. Reddy, P. S.; Sudarsanam, P.; Raju, G.; Reddy, B. M.; Catal. Commun. 2010, 11, 1224.

31. Reddy, P. S.; Sudarsanam, P.; Raju, G.; Reddy, B. M.; J. Ind. Eng. Chem. 2012, 18, 648.

Submitted: September 29, 2017

Published online: December 5, 2017 